\title{
Analysis of the Shear Force Distribution of Laminated Slab with Shear Keys Simply Supported on Four Sides
}

\author{
Li Ming \\ Shenyang, China \\ Jangho Group Co.,Ltd \\ Beijing, China \\ dingxianxing@126.com \\ Wang Chunyan \\ Shenyang, China \\ 742739583@qq.com \\ Tao Wei \\ Jangho Group Co.,Ltd \\ Beijing, China \\ taowei@jangho.com
}

Civil Engineering College Shenyang Jianzhu Univercity

Civil Engineering College Shenyang Jianzhu Univercity

\begin{abstract}
Prefabricated concrete structure has the advantages of being constructed fast, high quality, energy conservation, good seismic performance and environmental protection, etc. It is the developing direction of the future buildings. It's one of the important research content of prefabricated concrete structure to study the prefabricated components, of which precast floor is the most important one. At present, steel truss composite slab is adopted in most of the structures. Its integrity performance is good, but it has the shortcomings like the dosage of steel, the slab being very thick and so on. Therefore, a new type of laminated slab with shear keys is put forward, of which the shear keys is used to replace the steel truss to make sure the integrity of laminated slab. It can reduce the steel dosage and make the slab thin, which will save the cost of the whole building. In order to make it clear how the shear keys work in the laminated slab, the shear distribution of the shear keys along the $X$ direction and along the $Y$ direction of laminated slab is analyzed. The results show that: along the $X$ direction and along the $\mathrm{Y}$ direction, the shear at the outermost lines changes with no obvious regularity compared with the inner three ones and its value is negative or positive; from the second to the fourth lines, the shear changes in some regularity; the shear keys can connect the precast layer and cast-in-place layer of the laminated slab well.
\end{abstract}

Keywords-Laminated slab; shear key; shear distribution; precast layer; cast in place layer

\section{INTRODUCTION}

Prefabricated concrete structure is composed of the precast concrete structure as main component and part of cast-in- place concrete structure. Prefabricated concrete structure has the advantages of being constructed fast,

\author{
Wang Bin \\ Jangho Group Co.,Ltd \\ Beijing, China \\ wangbin06@jangho..com
}

\author{
Sun Zhezhe \\ Civil Engineering College \\ Shenyang Jianzhu Univercity \\ Shenyang, China \\ 912749302@qq.com
}

high quality, energy conservation, good seismic performance and environmental protection etc. , and it is the developing direction of the future building[1-11]. Reinforced concrete laminated slabs as its important horizontal force component becomes one of the main objects of study. At present, steel truss laminated slab is mostly used as prefabricated concrete floor in China [4]. Because precast and cast-in-place parts of steel truss laminated slab is connected by steel truss, the dosage of steel bar is increased largely. And also the steel truss of this kind of slab is higher in order to ensure the connection of precast and cast-in-place section reliable, which results in the overall slab thicker than the general cast-in-site slab. So it increases a lot of consumption of building materials and makes the cost of building increased accordingly. To solve these problems, a new type of laminated slab with shear keys is put forward, of which the shear keys are used to replace the steel truss and to make sure the integrity of laminated slab. It can reduce the steel dosage and slab thickness, which will reduce the cost of building [5]. Therefore, the mechanical property of the laminated slab is analyzed in the following.

\section{CONSTRUCTION OF LAMINATED SLAB WITH SHEAR KEYS}

Reinforced concrete laminated slab with shear keys is made of the precast reinforced concrete slab, precast concrete shear keys, and cast-in-place reinforced concrete laminated layer. The shear keys are embedded in the precast slab, as shown in Fig .1 (a).The cast-in-site 
laminated layer is as shown in Fig .1 (b). The laminated slab is composed of the above two parts. The precast slab and the laminated layer are connected by the shear keys and the shear and pulling force between these two parts are delivered by the shear keys, which ensures the integrity of the laminated slab.

\section{FINITE ELEMENT SIMULATION METHOD}

The common finite element software ABAQUS is used to simulate the load process of the laminated slab [6-8]. In the simulating, the following conditions are adopted: the concrete damage plasticity model provided by software is used as the constitutive relation of concrete; uniaxial tensile and compressive stress - strain relation is get via the current concrete specification [6-8]; double broken line model of the second line level is adopted as the constitutive relation of reinforcement; the degree freedom of reinforcement and concrete are coupled by Embedded Region technology; entity element C3D8R layer are used in precast slab, shear keys and laminated slab model; element T3D2 is used in reinforcement model; Between the precast slab and the cast-in-place layer, the General Contact as exposure is used, of which the contact properties is as "hard" contact, i.e. when the contact pressure reaches to zero or negative, the two interface will separate, and remove the untying in corresponding nodes; contact friction coefficient is zero. Solution is obtained by Newton's method of implicit solver.

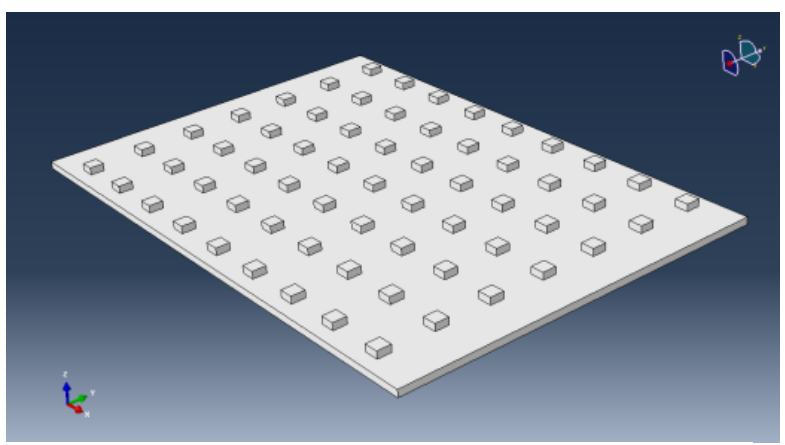

(a)precast slab with shear reinforced concrete keys

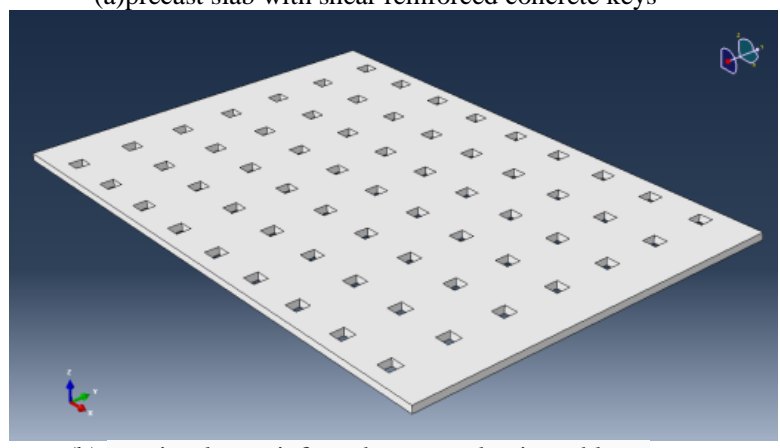

(b) cast-in-place reinforced concrete laminated layer

Figure 1. Model of reinforced concrete laminate slab with shear keys

\section{SHEAR DISTRIBUTION OF LAMINATED SLAB SIMPLY SUPPORTED ON FOUR SIDES}

To analyze the shear distribution of laminated slab, a laminated slab is designed. Its geometry size and material parameters are as follows: plane size is $2700 \mathrm{mmx} 3900 \mathrm{~mm}$; thickness is $100 \mathrm{~mm}$; shear key size is $100 \mathrm{~mm} \times 100 \mathrm{mmx} 100 \mathrm{~mm}$; the center of one shear key to the adjacent one is $400 \mathrm{~mm}$ in the $\mathrm{X}$ direction; the center of one shear key to the adjacent one is $300 \mathrm{~mm}$ in the $\mathrm{Y}$ direction, shown as Fig .2; the width of edge $\mathrm{t}$ is $100 \mathrm{~mm}$, arranged in the form shown as Fig .1; the strength grade of precast concrete slab and shear keys are $\mathrm{C} 40$ in Chinese code; the strength grade of cast-in-place concrete laminated layer is C30; a double-layer two-way reinforcement is adopted in the precast concrete floor and cast-in-place concrete laminated layer; the grade of reinforcement is HRB400 in Chinese code; the diameter of the reinforced bars are $10 \mathrm{~mm}$ and are spaced $200 \mathrm{~mm}$; the thickness of protective layer is $15 \mathrm{~mm}$; physical and mechanical parameters of concrete and steel value are gotten by referencing the existing reinforced concrete and steel structure specification [6-8]. Supporting conditions is that the slab is simply supported on four sides. For the convenience of description, shear keys in the slab are numbered as shown in Fig .2.

A. Shear distribution in the $X$ direction

Distribution of shear keys in the $\mathrm{X}$ direction is shown in Fig .3 to Fig .6. It can be seen from the Figures: the shear of the shear keys in the first line near to the edge of the slab along the $\mathrm{X}$ direction is positive, which is caused by the deformation of the cast-in-place layer is larger than the precast layer; yet the shear keys in the second, third and fourth lines along the $\mathrm{X}$ direction are negative, because the precast layer deforms earlier than the cast-in-place layer; the shear of the shear keys in the first line has no obvious distribution regality because the edge effect,; yet the shear keys in the other three lines has some distribution regality, i.e. at the beginning of loading, the shear of the shear keys linearly increases with the increase of distributed uniformly load, of which the relationship of the shear value and the growth rate is shown as equation (1) ; during the process of loading, the shear keys in the first line plays important role at first, then the second line plays important role, yet shear that the shear keys borne in the third and fourth lines is always small in the whole loading process; the maximum shear value of the three other lines is almost the same with each other except the first line; According to the theory of symmetry, the shear value of the shear keys in the symmetry axis of the slab along the $\mathrm{X}$ direction is zero, which shows it has no shear bearing effect.

The first line ( K12、K13、K14) > The line $(\mathrm{K} 22 、 \mathrm{~K} 23 、 \mathrm{~K} 24)>$ The third line

$(\mathrm{K} 32 、 \mathrm{~K} 33 、 \mathrm{~K} 34)>$ The fourth line $(\mathrm{K} 42 、 \mathrm{~K} 43$ 、 K44)
(1) 


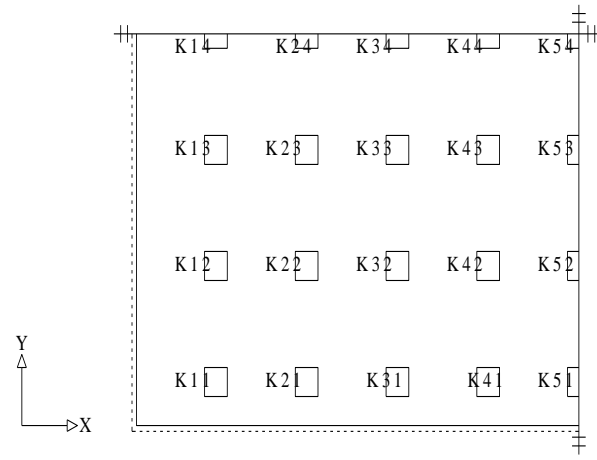

Figure 2. Number of shear keys

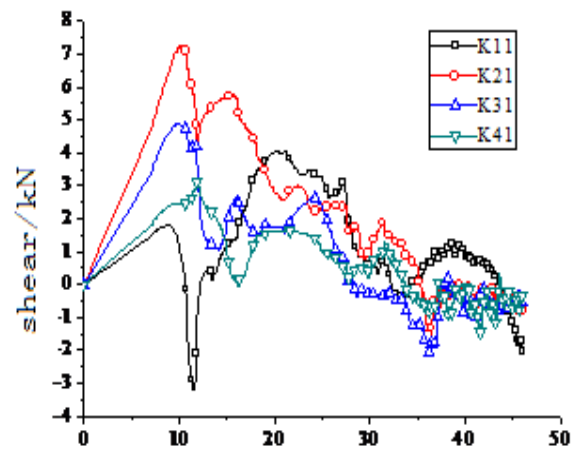

Uniformly distributed load $\left(\mathrm{kN} / \mathrm{m}^{2}\right)$

Figure 3. Shear of K12-K42

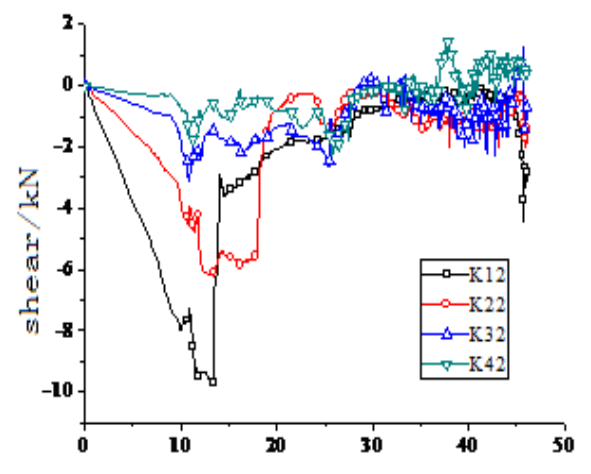

Uniformly distributed load $\left(\mathrm{kN} / \mathrm{m}^{2}\right)$

Figure 4. Shear of K12-K42

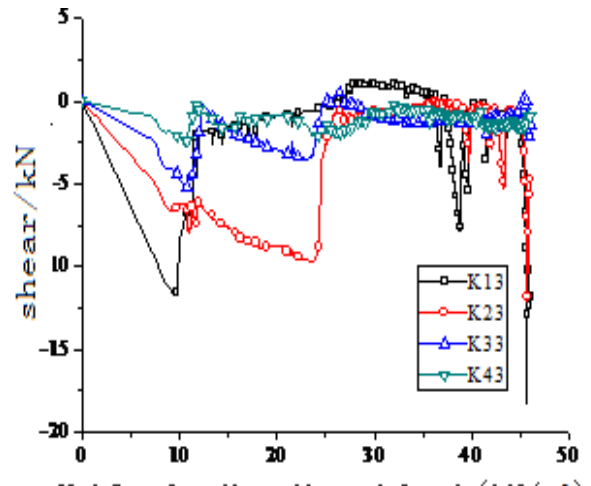

Uniformly distributed load $\left(\mathrm{kN} / \mathrm{m}^{2}\right)$

Figure 5. Shear of K13-K43

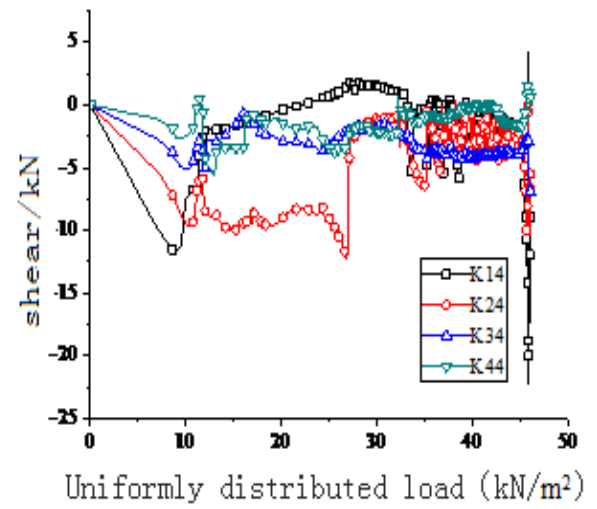

Figure 6. hear of K14-K44

\section{B. Shear distribution in the $Y$ direction}

Distribution of shear keys in the $\mathrm{Y}$ direction is shown in Fig .7 to Fig .10. It can be seen from the Figures: the shear of the shear keys in the first row near to the edge of the slab along the $\mathrm{Y}$ direction is positive or negative, which has no obvious regularity in changing compared with the other three rows; yet the shear keys in the second, third and fourth rows along the $\mathrm{Y}$ direction has some regularity, i.e. during the early stage of loading, the shear of the shear keys linearly increases with the increase of distributed uniformly load, of which the relationship of the shear value and the growth rate is shown as equation (2) ; during the process of loading, the shear keys in the first row plays important role at first, then the second row plays important role, and the max shear value of the second row is bigger than the first ones; in the later stage of loading, the shear keys of the first and the third rows play important role in bearing, and the shear of the shear keys increase with the shear keys far away from the edge. According to the theory of symmetry, the shear value of the shear keys in the symmetry axis of the slab along the $\mathrm{Y}$ direction is zero, which shows it has no shear bearing effect.

The first row $(\mathrm{K} 21, \mathrm{~K} 31, \mathrm{~K} 41)=$ the second row $(\mathrm{K} 22$, $\mathrm{K} 32, \mathrm{~K} 42)>$ the third row $(\mathrm{K} 23, \mathrm{~K} 33, \mathrm{~K} 43)$

\section{CONCLUSIONS AND PROSPECT}

Based on the above analysis, the following conclusions can be gotten:

Along the $\mathrm{X}$ direction and $\mathrm{Y}$ direction, the shear of the shear keys at the first line or row at the edge of the slab, the shear of the shear keys are negative or positive at the beginning of loading.

Along the $\mathrm{X}$ direction or the $\mathrm{Y}$ direction, the shear of the first line or row has no obvious changing regularity with the change of load, yet the shear of the second to the forth line or row has some changing regularity with the change of load. The changing regularity is as: ( K12, $\mathrm{K} 13, \mathrm{~K} 14)>(\mathrm{K} 22, \mathrm{~K} 23, \mathrm{~K} 24)>(\mathrm{K} 32, \mathrm{~K} 33, \mathrm{~K} 34)>$ 
(K42, K43, K44) or (K21, K31, K41) > (K22, K32, $\mathrm{K} 42)>(\mathrm{K} 23, \mathrm{~K} 33, \mathrm{~K} 43)$.

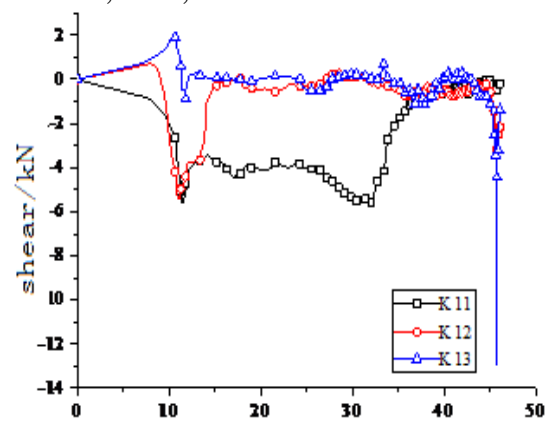

Uniformly distributed load $\left(\mathrm{kN} / \mathrm{m}^{2}\right)$

Figure 7. Shear of K11-K13

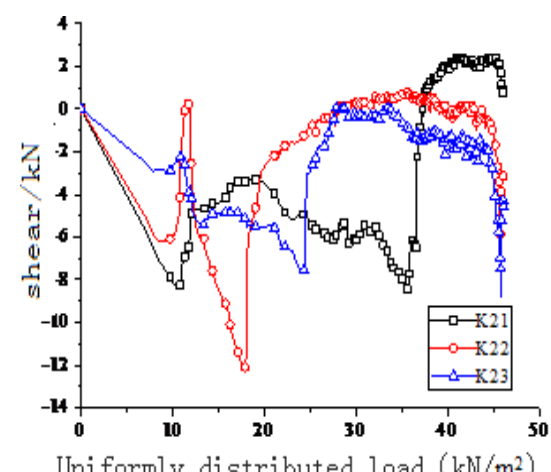

Figure 8. Shear of K21-K23

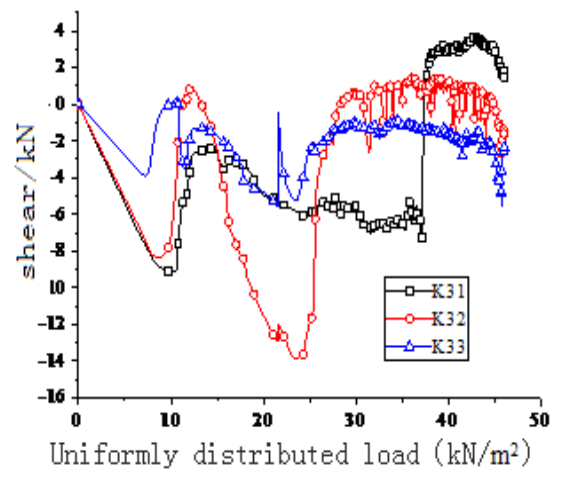

Figure 9. Shear of K31-K33

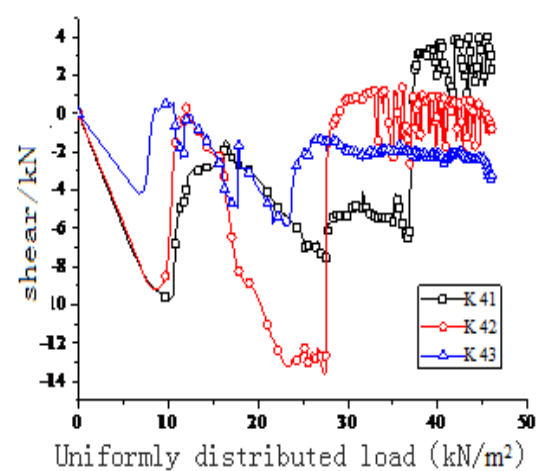

Figure 10. Shear of K41-K43
During the process of loading, along the $\mathrm{X}$ direction, the shear keys of first line play important row in the early stage, then shear of the second ones, yet the shear of the third and the fourth lines are small in the whole loading process; along the $\mathrm{Y}$ direction, during the process of loading, the shear keys in the first row plays important role at first, then the second row plays important role, and the max shear value of the second row is bigger than the first ones; in the later stage of loading, the shear keys of the first and the third rows play important role in bearing, and the shear of the shear keys increase with the shear keys far away from the edge.

\section{ACKNOWLEDGEMENT}

This work was financially supported by China Postdoctoral Science Foundation funded project and Beijing Postdoctoral Research Foundation

\section{REFERENCES}

[1] Du Jian. "Prestressed concrete two-way laminated slab flat-fell seam lap experimental study ". Tianjin university engineering college, 2007-6.

[2] Liu Tie. "Messenger steel bar truss concrete composite plate performance study". Zhejiang: Zhejiang university, 2006:3-6.

[3] ZHAO Chenwen, CHEN Hongliang, GAO Lianyu, LI Yong. "Study on Behaviors and Application of Pre-stressed Concrete Hollow Core Laminated Slab". Journal of Shenyang Jianzhu University(Natural Science),2005-7.

[4] Zhao Lei. "Messenger steel bar truss concrete laminated slab design calculation method research". Hunan: central south university, 2007:10 -17.

[5] Zhuang Zhuo, Zhang Fan, CenSong. "ABAQUS nonlinear finite element analysis and instance". Beijing: science press, 2005.

[6] Shi Yiping Zhou Yurong. "ABAQUS finite element analysis of example explanation". Beijing: mechanical industry publishing house, 2006

[7] Wang Yuguo, Fu Chuanguo. "ABAQUS structural engineering analysis and example explanation"]. Beijing: China building industry press, 2010.

[8] HU Jinjun, Xie Lili. "Review of rupture directivity related concepts in seismology". Earthquake Engineering and Engineering Vibration, 2011, 31(4):1-8.

[9] HU Jin-Jun, XIE Li-Li. "Directivity in the basic parameters of the near-field acceleration ground motions during the Wenchuan earthquake". Chinese J.Geophys.2011,V54(10):2581-2589.

[10] Wang Yuanqing, YUAN Xia, ZHANG Yannian, LIU Ming. "Analysis of Loading Capacity of Steel Bar Truss and Concrete Superimposed Two-Way Slab". Journal of Shenyang Jianzhu University(Natural Science),2014-3.

[11] ZHOU Baofeng, SONG, Tingsu, Wen ,Ruizhi XIE Lili. "Permanent Displacement Identification Analysis in 2011 Mw9.0 Tohoku Earthquake, Japan". Applied Mechanics and Materials,2014,580:1533-1537. 